\title{
Restoring Rivers One Reach at a Time: Results from a Survey of U.S. River Restoration Practitioners
}

\author{
Emily S. Bernhardt, ${ }^{1,2,3}$ Elizabeth B. Sudduth, ${ }^{1,4}$ Margaret A. Palmer, ${ }^{3,5}$ J. David Allan, ${ }^{6}$ \\ Judy L. Meyer, ${ }^{4}$ Gretchen Alexander, ${ }^{5}$ Jennifer Follastad-Shah ${ }^{1,7}$ Brooke Hassett, ${ }^{1,3}$ \\ Robin Jenkinson, ${ }^{8}$ Rebecca Lave, ${ }^{9}$ Jeanne Rumps, ${ }^{10}$ and Laura Pagano ${ }^{9}$
}

\begin{abstract}
Despite expenditures of more than 1 billion dollars annually, there is little information available about project motivations, actions, and results for the vast majority of river restoration efforts. We performed confidential telephone interviews with 317 restoration project managers from across the United States with the goals of (1) assessing project motivations and the metrics of project evaluation and (2) estimating the proportion of projects that set and meet criteria for ecologically successful river restoration projects. According to project managers, ecological degradation typically motivated restoration projects, but post-project appearance and positive public opinion were the most commonly used metrics of success. Less than half of all projects set measurable objectives for their projects, but nearly twothirds of all interviewees felt that their projects had been
\end{abstract}

"completely successful." Projects that we classified as highly effective were distinct from the full database in that most had significant community involvement and an advisory committee. Interviews revealed that many restoration practitioners are frustrated by the lack of funding for and emphasis on project monitoring. To remedy this, we recommend a national program of strategic monitoring focused on a subset of future projects. Our interviews also suggest that merely conducting and publishing more scientific studies will not lead to significant improvements in restoration practice; direct, collaborative involvement between scientists, managers, and practitioners is required for forward progress in the science and application of river restoration.

Key words: evaluation, interviews, monitoring, NRRSS, river restoration, success.

\section{Introduction}

Restoration of rivers and streams is an increasingly common approach to managing U.S. freshwaters, a trend that reflects a growing awareness of river degradation (U.S. EPA 2000) and societal desires for waterways that provide beneficial human uses although sustaining biodiversity and ecosystem goods and services (NRC 1992; Postel \& Richter 2003; Bernhardt et al. 2005). River restoration is a term applied to a wide range of specific management activities, from replanting riparian trees or fencing live-

\footnotetext{
${ }^{1}$ Department of biology, BOX 90338, Duke University, Durham, NC 27708, U.S.A.

${ }^{2}$ Address correspondence to E. S. Bernhardtt, email emily.bernhardt@duke.edu ${ }^{3}$ Departments of Entomology and Biology, Plant Sciences Building, University of Maryland, College Park, MD 20742, U.S.A.

${ }^{4}$ Institute of Ecology, 517 Biological Sciences Bldg., University of Georgia, Athens, GA 30602, U.S.A.

${ }^{5}$ Chesapeake Biological Laboratory, University of Maryland Center for Environmental Science, P.O. Box 38, Solomons, MD 20688, U.S.A.

${ }^{6}$ School of Natural Resources \& Environment, University of Michigan, Ann Arbor, MI 48109, U.S.A.

${ }^{7}$ Department of Biology, University of New Mexico, Albuquerque,

NM 87131, U.S.A.

${ }^{8}$ Department of Fish and Wildlife Resources, University of Idaho, Moscow, ID 83844, U.S.A.

${ }^{9}$ Department of Geography, McCone Hall, University of California, Berkeley, CA 94720, U.S.A.

${ }^{10}$ Center for Ecohydraulic Research, College of Engineering, 322 E. Front St., Suite 340, University of Idaho, Boise, ID, U.S.A.
}

stock out of stream corridors to the removal of dams and full-scale redesign of river channels.

Despite rapid increases in river restoration funding and activity throughout the United States over the last 30 years, there has been little evaluation of river restoration outcomes (Bernhardt et al. 2005). The need for assessing river restoration costs and benefits is nearly universally appreciated (e.g., Kondolf 1995; Kondolf \& Micheli 1995; Bash \& Ryan 2002; Downs \& Kondolf 2002; Palmer et al. 2005; Ruiz-Jaen \& Mitchell Aide 2005). Although our scientific understanding of river ecosystems is becoming increasingly sophisticated, too little of this understanding is being translated or applied in the context of restoration projects (Pedroli et al. 2001; Wohl et al. 2005).

The National River Restoration Science Synthesis (NRRSS) working group was formed in 2001 to evaluate river restoration in the United States from a scientific perspective. As a first step, we set the goal of summarizing restoration activity for seven large regions of the country ("nodes"). We compiled approximately 37,000 records on river restoration projects from some approximately 800 data sources into an extensively calibrated common field database (Bernhardt et al. 2005) (the "NRRSS summary database"). We found that river restoration efforts are growing exponentially in every region of the United States and that more than 1 billion dollars a year are invested in efforts to restore our nation's rivers (Bernhardt et al. 2005). The data synthesis effort was initially motivated 
by a desire to determine the common elements of ecologically successful restoration projects, yet it was impossible to perform this analysis with existing records. Only $10 \%$ of project records indicated any form of monitoring, and specific monitoring information was rarely available (Bernhardt et al. 2005). We found little written documentation about the majority of river restoration projects and where written records exist (and they can be extensive), they typically exist as single copies on the shelves and in filing cabinets of practitioners and management agencies. Therefore, we designed an extensive telephone interview protocol to obtain detailed information on a randomly selected subset of river restoration projects from the NRRSS Summary Database.

Here, we show that there is a large discrepancy between the rates of monitoring reported in written records versus the rates obtained from interviews with project contacts. We discuss the relationship between the motivation, the implementation, and the assessment of restoration projects as revealed to us through interviews. We argue that the enterprise of river restoration has been weakened by a lack of incentives and requirements for collecting and disseminating information on project outcomes. We recommend a national program of strategic monitoring on a subset of future projects to gather the information needed for effective restoration and adaptive management of streams and rivers. We contend that even projects that are primarily motivated by public needs and concerns can provide ecological benefits-these are not incompatible goals, and truly successful projects can accomplish both (e.g., Palmer et al. 2005).

\section{Methods}

\section{Building the NRRSS Summary Database of Project Records}

A full description of the methods for building this database is available online (http://www.restoringrivers.org/ newsite/nbii.html) as supplemental online material to Bernhardt et al. (2005). Briefly, in 2002, our working group designed a database that (1) contained the information fields found within existing large restoration databases and (2) additional fields of interest to our scientific working group and nongovernmental organization (NGO) partners. This database is now publicly available at www. nrrss.nbii.gov. The goal of NRRSS was to understand the current state of restoration in the United States; thus, the definitions of "project" and "stream restoration" were left up to the data source-no judgments were made of the validity of the term stream restoration, and there was no standardized size or cost unit for projects.

Projects were included in the NRRSS database if they were conducted for the purpose of improving stream conditions and if the effort could be evaluated (e.g., some intervention or effort took place in the field). For project records that were not acquired as part of a stream restoration-specific database, our decision to include them was based on whether (1) the record contained either a statement of intent or actions implemented and (2) this information indicated an intent of restoring or improving stream conditions and explicitly mentioned riparian or stream activities. The single subjective field in the NRRSS Summary Database was the project goal. Projects were categorized based on their listed goal(s) (motivations, intents, or purpose) into one or more of 13 goal categories (Table 1). All members of the working group participated in extensive calibration of our classification approach.

Care was taken to remove duplicate records for the same project prior to database analysis. Our objective was to achieve a database that was representative of the goals and geographic variability of stream restoration activities within the seven nodes rather than a comprehensive database. To validate the representativeness of our regional databases, we sent data summaries (showing geographic distribution of projects and basic statistics for project costs and intents) to stream restoration experts (e.g., county watershed managers, drain commissioners, state natural resource managers) in each node. Experts who saw a weakness in the completeness or representativeness of the data were asked to provide suggestions of further data sources or contacts which the working group members then followed up on to complete the database.

\section{Building the NRRSS Interview Database for a Subset of Projects}

Eligibility. Projects within the NRRSS Summary Database were eligible for selection for a follow-up interview if they (1) occurred within one of the 23 states contained in our seven regional nodes; (2) were implemented or completed between 1996 and 2002; (3) had information about a project contact (e.g., an individual or agency name allowing follow-up); and (4) listed at least one of the four selected project goals (riparian management, water quality management, in-stream habitat improvement, or channel reconfiguration). We selected these goal categories because they were dominant categories within the summary database and because they had an implicit goal of improving ecological conditions (as opposed to goals such as stormwater management or bank stabilization that are directed more explicitly toward physical or hydrologic endpoints).

Selection. Selection was performed independently within each regional node. Beginning with the goal category containing the smallest number of projects, all projects meeting the above-described eligibility requirements within that category were assigned a random number. Attempts were made to schedule an interview with the listed project contact beginning with the lowest assigned number in each category. Once an interview was conducted, that project record was removed from the pool of candidate projects (e.g., a project that was selected as a riparian management project could not subsequently be selected as a water quality project although both goals might be listed for the 
Table 1. NRRSS working group list of goal categories and operational definitions.

Aesthetics/Recreation/Education: Activities that increase community value: use, appearance, access, safety, and knowledge.

Bank Stabilization: Practices designed to reduce/eliminate erosion or slumping of bank material into the river channel.

This category DOES NOT include stormwater management, see next intent category.

Channel Reconfiguration: Alteration of channel plan form or longitudinal profile and/or daylighting (converting culverts and pipes to open channels). Includes stream meander restoration and in-channel structures that alter the thalweg of the stream.

Dam Removal/Retrofit: Removal of dams and weirs or modifications/retrofits to existing dams to reduce negative ecological impacts. Excludes dam modifications that are simply for improving Fish Passage.

Fish Passage: Removal of barriers to upstream/downstream migration of fishes. Includes the physical removal of barriers and also construction of alternative pathways. Includes migration barriers placed at strategic locations along streams to prevent undesirable species from accessing upstream areas.

Floodplain Reconnection: Practices that increase the flood frequency of floodplain areas and/or promote flux of organisms and material between riverine and floodplain areas.

Flow Modification: Practices that alter the timing and delivery of water quantity (DOES NOT include "Stormwater Management"). Typically, but not necessarily associated with releases from impoundments and constructed flow regulators.

In-stream Habitat Improvement: Altering structural complexity to increase habitat availability and diversity for target organisms and provision of breeding habitat and refugia from disturbance and predation. (In some cases, habitat improvement may be an action with the intent of In-stream Species Management; in other cases, Habitat Improvement may be the intent and might be accomplished through Channel Reconfiguration; be very careful to separate action from intent when deciding whether to select this category.)

In-stream Species Management: Practices that directly alter aquatic native species distribution and abundance through the addition (stocking) or translocation of animal and plant species and/or removal of exotics. Excludes physical manipulations of habitat/breeding territory (see In-stream Habitat Improvement).

Land Acquisition: Practices that obtain lease/title/easements for streamside land for the explicit purpose of preservation or removal of impacting agents and/or to facilitate future restoration projects. Note: Simple purchase and preservation to prevent potential future land conversion are insufficient for inclusion in the NRRSS database. NRRSS projects should demonstrate intended or actual cessation of detrimental activities in acquired land or active restoration components.

Riparian Management: Revegetation of riparian zone and/or removal of exotic species (e.g., weeds, cattle). Excludes localized planting only to stabilize bank areas (see Bank Stabilization).

Stormwater Management: Special case of Flow Modification that includes the construction and management of structures (ponds, wetlands, and flow regulators) in urban areas to modify the release of storm run-off into waterways from watersheds with elevated imperviousness into waterways. These practices/structures generally aim to reduce peak flow magnitudes and extend flow duration. For the purposes of NRRSS, "Stormwater Management" refers to water quantity not quality. Urban sediment, litter, and temperature control should be categorized as Water Quality Management.

Water Quality Management: Practices that protect existing water quality or change the chemical composition and/or suspended particulate load. Remediation of acid mine drainage falls into this category as does Combined Sewer Overflow separation. Excludes urban run-off quantity management (see Stormwater Management).

project). A project was dropped from the interview pool after more than five unsuccessful attempts to locate or contact the project manager or if the contact person for a project had previously been interviewed about another project. More than 800 projects had to be dropped in the process of conducting 317 interviews, usually because it was impossible to elicit a response from the project contact after five separate attempts (Table 2). Interviews were conducted until the node had completed 12 interviews within each target category or until there were no additional projects within a category eligible for selection.

Interview Content. We designed our interview questionnaire through a group process of first identifying primary research questions about restoration motivations and evaluation. Decisions about interview content and protocol were made consistent with best practices in social science research (Heppner et al. 1992; Leong \& Austin 1996; R. Fassinger, Counseling and Personnel Services Department, University of Maryland, personal communication, April 2004). We agreed that we wished to explore the role of science in restoration (both the scientific process and the use of published information), the extent and types of project evaluation that were occurring, evaluation of success, and lessons learned. Prior restoration surveys were very influential in this process (Bash \& Ryan 2002; Moerke \& Lamberti 2004). A large number of questions were then grouped by topic area and reduced in number to ensure that interviews could be completed in approximately 30 minutes. The interview was then reviewed by an expert in interview design and interpretation (R. Fassinger, Counseling and Personnel Services Department, University of Maryland) to ensure that questions were phrased appropriately and would not lead or mislead the interviewee. 
Table 2. Number of project interviews completed and attempted in each node and the classification of reasons for abandoning projects.

\begin{tabular}{|c|c|c|c|c|c|c|}
\hline \multirow[b]{2}{*}{ Node } & \multirow[b]{2}{*}{$\begin{array}{l}\text { \# of Interviews } \\
\text { Completed }\end{array}$} & \multirow[b]{2}{*}{$\begin{array}{c}\text { \# of Selected } \\
\text { Projects Abandoned }\end{array}$} & \multicolumn{4}{|c|}{ Reason for Abandoning Project } \\
\hline & & & $\begin{array}{c}\text { No } \\
\text { Response }\end{array}$ & $\begin{array}{l}\text { Unwilling/Unable } \\
\text { to Participate }\end{array}$ & $\begin{array}{l}\text { Project Not } \\
\text { Implemented }\end{array}$ & $\begin{array}{c}\text { Subject } \\
\text { Previously Interviewed }\end{array}$ \\
\hline California & 44 & 358 & 270 & $12^{a}$ & 0 & 76 \\
\hline Central U.S. large rivers & 48 & 146 & 100 & 5 & 11 & 30 \\
\hline Chesapeake Bay & 47 & 109 & 44 & 6 & 16 & 43 \\
\hline Southwest & 48 & 101 & 29 & 20 & 18 & 34 \\
\hline Upper Midwest & 39 & 119 & 14 & 4 & 3 & 97 \\
\hline
\end{tabular}

${ }^{a}$ In nine of these cases, the original project manager had left the agency, and new staff had insufficient knowledge of the project.

${ }^{b}$ Eleven of these did not participate because the project they were asked about was not really river restoration, although funded with restoration monies.

The interview was pilot tested on one or two willing project contacts from within each node, with the agreement that these data would not be included in our database. Tapes of these initial interviews were shared and discussed at a working group meeting in May 2004, allowing us to eliminate redundant questions, rephrase or provide standard prompts for confusing questions, and revise the answer choices to better reflect standard responses (Frary 1985). The format was finalized in May 2004 and subsequently underwent Institutional Review at all seven participating universities to ensure compliance with accepted protocols for studies with human subjects. Interviews began in September 2004 and were completed by August 2005. The official NRRSS interview form is available at www.restoringrivers.org.

We conducted interviews by phone because prior studies suggested that subjects provide more "honest" responses in telephone interviews as compared to mail or face-to-face surveys, and response rates are generally higher (Yu \& Cooper 1983). Also, our interviews covered a very broad geographic scope, and face-to-face interviews would have been impractical.

Phone Interview Procedures. At the first contact, a project manager was read a script describing the goals of the NRRSS project and our selection of their project for indepth evaluation. If the manager agreed to participate in the interview, they were sent a one-page summary of the interview themes along with a confidentiality agreement explaining that their name and any identifying information would not be retained and that all project results would be discussed in aggregate form. If the project manager agreed to participate, a time was scheduled at their convenience to perform the interview. Each phone interview was taped (with the knowledge and permission of the interview subject) to facilitate data entry and quality assurance. Interviews typically lasted between 25 and 60 minutes.

Each interviewee was asked the same questions in the same order, and care was taken to ensure that all interviewers complied with the prepared script. To ensure that all interviewers followed a common format, we prepared a script for the initial contact and for the interview itself. Through our initial calibration process, we developed standard prompts for defining terms or clarifying questions when asked by the interviewee. For most questions, we asked the question and allowed an open-ended response that was then classified into a category by the interviewer. If necessary, interview subjects were prompted with example answers. Whenever the interviewer found it difficult to categorize an answer, they would ask the subject to select the appropriate response from the two most likely response categories. For a few questions, all response categories were provided and the reviewer was asked to choose one or rank between the supplied categories. Thus, the data consist of categorical responses to questions about project design, implementation and evaluation, and open text descriptions of monitoring methods and lessons learned.

All interview data were entered into a Microsoft Access database (structure available for download at www. restoringrivers.org), and each node stored identical but independent databases on a secure server at Duke University. Upon completion of all interviews, the seven databases were compiled into a single national interview database, and all identifying information (name of interviewee, project name, location of project) was removed from the database as required by Institutional Review Board guidelines. Results are discussed only in aggregate form.

\section{Interview Database Analysis}

We report responses to particularly informative individual queries, as well as combinatorial queries (e.g., of those who said "yes, monitoring occurred," what proportion used this information to evaluate project success). We have previously published guidelines for effective restoration (Palmer et al. 2005), suggesting that effective ecological restoration will (1) have a guiding image; (2) complete an ecological assessment; (3) demonstrate ecological improvements; (4) not cause lasting harm; and (5) increase the resiliency of the ecosystem. We devised a rubric for evaluating ecological effectiveness within the first three of these categories, having judged it impossible to assess 
whether a project had caused lasting harm or increased the resilience of the ecosystem based on the opinions and knowledge of project contacts. The purpose of this weighting scheme was 2 -fold. First, we wanted to use this procedure to identify projects that most closely matched our working definition of ecological success (fully described in Palmer et al. 2005) in order to look for common elements that might correlate with their high performance. Second, we wanted to compare these "ecologically successful" projects to those that project managers identified as successful.

Our rubric involved evaluating every project for specific attributes associated with each of the three success categories and assigning points for every attribute a project displayed. We began with the "guiding image" success category because we have proposed that the first step in river restoration should be articulation of a guiding image that describes the dynamic, ecologically healthy river that could exist at a given site (Palmer et al. 2005). To assess whether projects were informed by a guiding image, we awarded points to projects that (1) were based on a river management plan; (2) had a watershed assessment and management plan; (3) prioritized restoration for a particular site based on a broader vision for the river; (4) created their project design based on ecological impacts and opportunities; and (5) had clearly stated success criteria. Additional points were awarded for criterion 5 based on our subjective classification of whether the stated success criteria were quantifiable.

We next evaluated the "assessment" success category. Ecological success in a restoration project cannot be declared in the absence of clear project objectives from the start and subsequent evaluation of their achievement (Dahm et al. 1995; Palmer et al. 2005). Project scores for "ecological assessment" were based on the number, type, frequency, and duration of variables monitored, whether monitoring data were compared to a baseline or reference condition, whether monitoring data were analyzed and disseminated, and whether monitoring data were used to evaluate the project. Because many parameters may be monitored, there is no maximum score in this category.

Finally, we evaluated each project with respect to the "ecological improvement" success category. Ecologically successful restoration will induce measurable changes in physicochemical and biological components of the target river or stream that move toward the agreed-upon guiding image (Palmer et al. 2005). Projects were scored for their relative effectiveness at "ecosystem improvement" by awarding points for meeting success criteria that we classified as "ecological" (e.g., maintaining a desired channel dimension or preventing damage to a sewer pipe would not qualify, whereas improving water quality or finding more diverse biotic assemblages would qualify). Points were also assigned for having biological, chemical, or physical monitoring data that showed positive trends following restoration and for projects that were assessed as successful based on positive responses of ecological indicators.

\section{Results and Discussion}

We completed interviews with the project managers of 317 individual river restoration projects from around the country. Only two nodes were able to complete the full complement of 48 interviews, because there were insufficient eligible projects for interviews and/or because many projects within an interview category were abandoned (Table 2). The response rate for our survey can be calculated in two ways, of those projects selected, we achieved usable interviews for only approximately $25 \%$; however, in cases where we successfully made contact with a potential interviewee, $75 \%$ of contacted individuals elected to participate in our study. This response rate is well within the norm recommended for academic survey studies (Baruch 1999). Interview subjects (hereafter referred to as project contacts) played many roles within the restoration projects they were asked to comment upon but most commonly identified themselves as project coordinators $(72 \%$ of all subjects).

\section{Representativeness of the Interview Database}

Although we used a stratified random approach for the selection of candidate projects for interviews, the interviews that were actually performed (Table 3 ) represent a skewed subsample of summary database. Nearly $40 \%$ of projects were ineligible for selection, and we were unable to make contact with a number of the listed project contacts in our summary database. Projects in the interview database were significantly more expensive ( $\mathrm{t}$ test, $p=$ 0.03 ) and of a greater spatial extent ( $\mathrm{t}$ test, $p=0.04$ ) than those recorded for the summary database. Thus, the results of our interview database should not be extrapolated to the entire population of existing restoration projects because we expect that our interviews captured information on more in-depth and complex restoration efforts, conducted by staff with longer-than-average tenure at their respective employment. In consequence, the results from our interviews likely represent an optimistic

Table 3. The types of monitoring performed for projects in the NRRSS Interview Database.

\begin{tabular}{lcc}
\hline Monitoring Type & $\begin{array}{c}\text { \# of } \\
\text { Projects }\end{array}$ & $\begin{array}{c}\text { \% Survey } \\
\text { Projects }\end{array}$ \\
\hline Biological, chemical, physical & 61 & 19 \\
Biological, physical & 67 & 21 \\
Biological, chemical & 18 & 6 \\
Chemical, physical & 15 & 5 \\
Biological only & 46 & 15 \\
Physical only & 25 & 8 \\
Chemical only & 13 & 4 \\
Visual, photo only & 16 & 5 \\
\hline
\end{tabular}

Commonly monitored variables: Biological: fish $(n=87)$, macroinvertebrates $(n=76)$, and vegetation $(n=62)$; Chemical: general water quality $(n=43)$, $\mathrm{pH}(n=19)$, and nitrate $(n=19)$; and Physical: channel cross-sections $(n=$ 57), temperature $(n=37)$, and discharge $(n=31)$. 
view about the standard practice of river restoration in the United States.

\section{Project Motivations and Prioritization}

When gathering information for the NRRSS Summary Database, the majority of project records listed multiple reasons why the project was implemented, such that it was difficult or impossible to distinguish primary versus secondary goals. In the NRRSS Summary Database, the most commonly cited reasons for restoration were for water quality management $(27.0 \%)$ and riparian management $(26.5 \%)$ (Fig. 1). In contrast, within the survey dataset, the dominant primary project goals were water quality management $(26 \%)$ and in-stream habitat improvement
(18\%), with riparian management listed as the primary goal in only $8 \%$ of projects. This discrepancy likely reflects the fact that a large number of river restoration projects incorporate some form of riparian or floodplain tree planting as part of their implementation, such that riparian zones are improved without this necessarily being a primary or motivating goal for conducting the project.

Nearly half of all interviewees reported that projects were initiated because of a recognized need to address some form of river degradation. Others indicated that public safety issues and/or legal requirements (14\%) or funding availability (12\%) provided the primary motivation for the projects discussed. Only 41 of our 317 project interviews indicated that a project was legally mandated for mitigation purposes. Thus, of our sample, mitigation

A

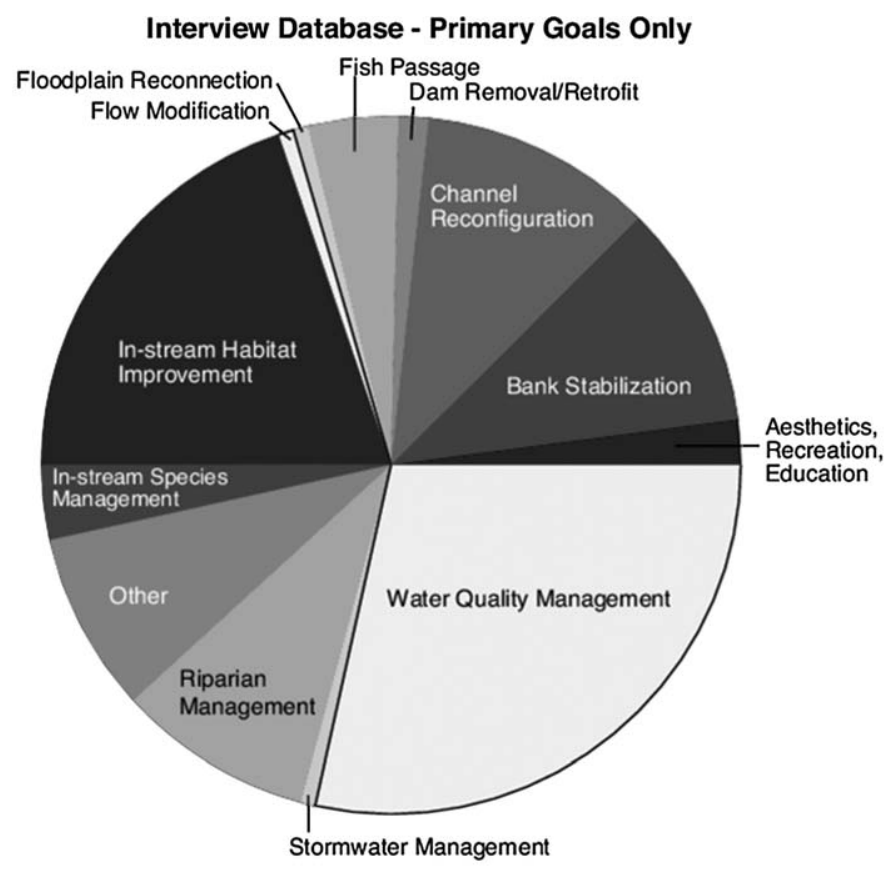

B

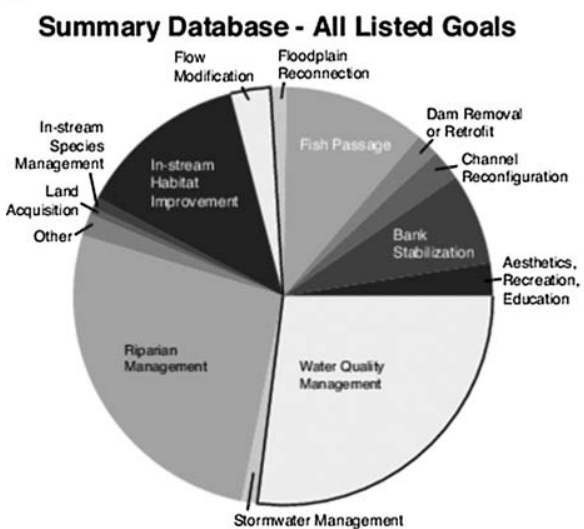

C

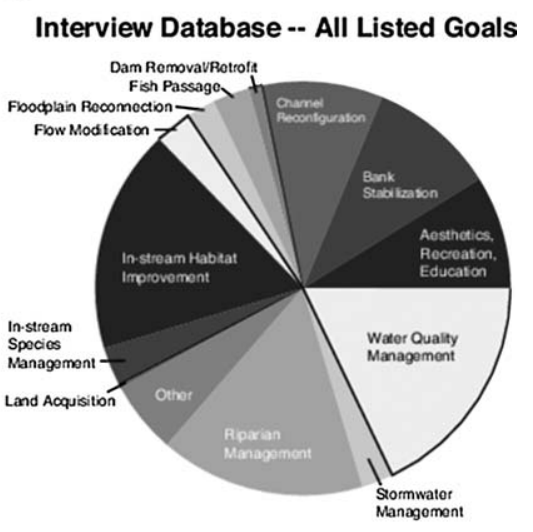

Figure 1. The distribution of project goals for (A) Primary goals from the NRRSS Interview Database; (B) All listed goals, NRRSS Summary Database; (C) All listed goals, NRRSS Interview Database. 
requirements did not drive the bulk of river restoration activity nationally. However, this varies regionally, with nearly half of all restoration projects in the Southeast (KY, GA, NC, SC) being implemented for mitigation purposes (Sudduth et al. 2007). Project contacts rarely reported that the principal reason that a project was initiated was because of a broader river or watershed management plan $(16 \%)$ or because it matched with an overarching agency mission (13\%), although these motivations were as likely to lead to project initiation as more pragmatic factors such as public safety concerns, mitigation requirements, or regulatory mandates (three combined factors, approximately $22 \%$ ).

The majority of projects in our interview database were conducted in watersheds where agriculture is the dominant land use (46\%). A surprisingly large proportion of restoration projects were implemented in undeveloped watersheds, wildlands, and protected areas (38\%), with a lesser proportion of projects implemented in urban or suburban watersheds (29\%). In most cases, the land on which the project was performed was privately owned $(53 \%)$.

Project contacts reported that on average, projects involved between seven and eight different entities as partners in the restoration process including, for example, federal, state and local government agencies, NGOs, private landowners, and volunteers. Most projects were funded by multiple entities (on average, 3.6 different funding agencies supported an individual restoration project), but the most common primary funders of restoration projects were federal and state agencies, each responsible for approximately $37 \%$ of all projects. Interviewees reported that the majority of projects also received in-kind contributions to the project.

\section{Project Design and Implementation}

Although project contacts rarely identified watershed management plans as the major motivation for individual restoration projects, more than half $(53 \%)$ of projects were conducted in watersheds where a watershed assessment had been conducted. Over one-third of all projects were said to be part of a larger watershed management plan, and of these, $73 \%$ had site-specific project goals that project contacts said completely overlapped with those of the watershed plan. More than two-thirds of all respondents said that their project was influenced by other projects within the same watershed. This suggests that although watershed plans may not be the primary stimulus for a restoration project, they play a major role in informing project design and implementation.

Interviewees reported that the two most important factors that determined which sites were selected for restoration projects were available land opportunities (22\%) and ecological concerns (21\%), with broader management goals such as a watershed plan or an overarching vision for the river of interest of minor importance in driving site selection (approximately 5\% combined). When asked what were the one or two most important factors in choosing the final project design, most respondents chose the categories of opportunities for ecological improvement $(41 \%)$ or ecological impacts $(29 \%)$, with constraints like location-specific limitations (26\%), availability of funds $(19 \%)$, or types of available expertise and past experience $(25 \%)$ also playing an important role.

Citizen groups were involved in 215 of the restoration projects in our database $(n=317)$, with practitioners characterizing the impact of their involvement as substantial in the initiation and implementation phases of a project in $30-40 \%$ of this subset of projects. Nearly half of all projects $(41 \%)$ had a formal advisory committee associated with the project-meaning that there was a group of people who met regularly to discuss the project distinct from those responsible for day-to-day project management. Most of these groups included agency scientists $(74 \%)$ and/or members of the public $(58 \%)$ with representatives from NGOs, academic institutions, and the private sector involved in less than one-third of all project advisory committees.

We found that practitioners rely on diverse sources of information because they develop and evaluate design plans, with the typical project design influenced by $2-3$ different sources of information. Thirteen percent of respondents said the most important source of knowledge they relied on was past experience. Another 16\% cited either agency guidelines or reports along with workshops or short courses as the single most important source of knowledge they relied on. Only one respondent made that claim for a peer-reviewed scientific journal article.

The vast majority of survey respondents $(84 \%)$ reported that they made significant efforts to minimize the environmental impacts of project construction. However, $60 \%$ of all respondents indicated that their projects, once implemented, needed on-going maintenance. Project contacts reported that there was no funding available for post-implementation maintenance for nearly one-third of the projects where such maintenance was required.

\section{Project Contact Assessment of Project Success}

Success in restoration can be evaluated from a variety of perspectives that range from community building to education to improving environmental conditions. From a scientific perspective, the ideal process for conducting a restoration project would ensure that regardless of project outcome, the maximum information would be gained to improve future efforts. Three criteria must be met for this to be the case: (1) the project must have a clearly defined goal (approximately expected outcome for the site); (2) a series of objective success criteria (hypotheses about what should happen as a result of the manipulation) must be proposed; and (3) the evaluation of project success must be based on analysis of a series of measurements appropriate to the success criteria made prior to and after project implementation at both the project 
site and an unimpacted reference site. Thirty-one of the 317 projects in our interview database (approximately $10 \%$ ) met this standard (Fig. 2). These 31 projects were distributed across six of our seven regional nodes (there were none in our interview sample from CA). Most of these projects fell into one of the three goal categories: water quality management (39\%), in-stream habitat improvement $(26 \%)$, and channel reconfiguration $(10 \%)$, with two bank stabilization and one in-stream species management project making up the full dataset. The average cost of these projects ( $\$ 1.9$ million) was not different from the full interview database average (\$1.8 million).

Although only $10 \%$ of all projects used the idealized approach outlined above, more than $65 \%$ of project contacts asserted that the project under discussion had been completely successful. For this question, respondents were asked "Do you consider this project successful?" and were provided with four possible answers: "completely successful," "partially successful," "too soon to tell," and "not at all successful." Our interview was designed to understand what information is being used to make this determination.

Nearly half of the project contacts indicated that their project had explicitly stated success criteria (173 of 317), yet few of the projects in our interview database $(18 \%)$ were evaluated based on whether or not these success criteria were met. In many cases, our post hoc classification of stated success criteria found them to be either inappropriate (for 29 projects, stated criteria were merely restate- ments of project design plans-e.g., "plant 700 trees") or nonquantitative (for 95 projects, it was not possible to evaluate criteria with any field measurements-e.g., "establish a natural channel").

Project monitoring can have many meanings to those involved in restoration. Monitoring is required in some cases in order to acquire initial permits (permit monitoring); implementation monitoring is often done to determine whether implemented structures or forms or planted vegetation are serving their desired function; and outcome monitoring is done to determine whether success criteria or broader project goals are being accomplished as a result of the project. For most projects in the interview database $(83 \%)$, project contacts indicated that some monitoring data specific to their project had been collected. Nearly $20 \%$ of these monitored projects collected a combination of biological, chemical, and physical data (Table 3). Photographic or visual monitoring was a part of many projectmonitoring efforts and was the only source of data for project evaluation for $5 \%$ of monitored projects (Table 3 ). The majority of project contacts indicated that their projects were monitored both before and after construction $(69 \%)$, and nearly $30 \%$ included associated monitoring at a reference site (Table 4 ). For $7 \%$ of the projects in the interview database, all associated project monitoring was done prior to project implementation. This monitoring is likely associated with the permitting process.

The interview database analysis suggests that extensive monitoring data were collected for the majority of

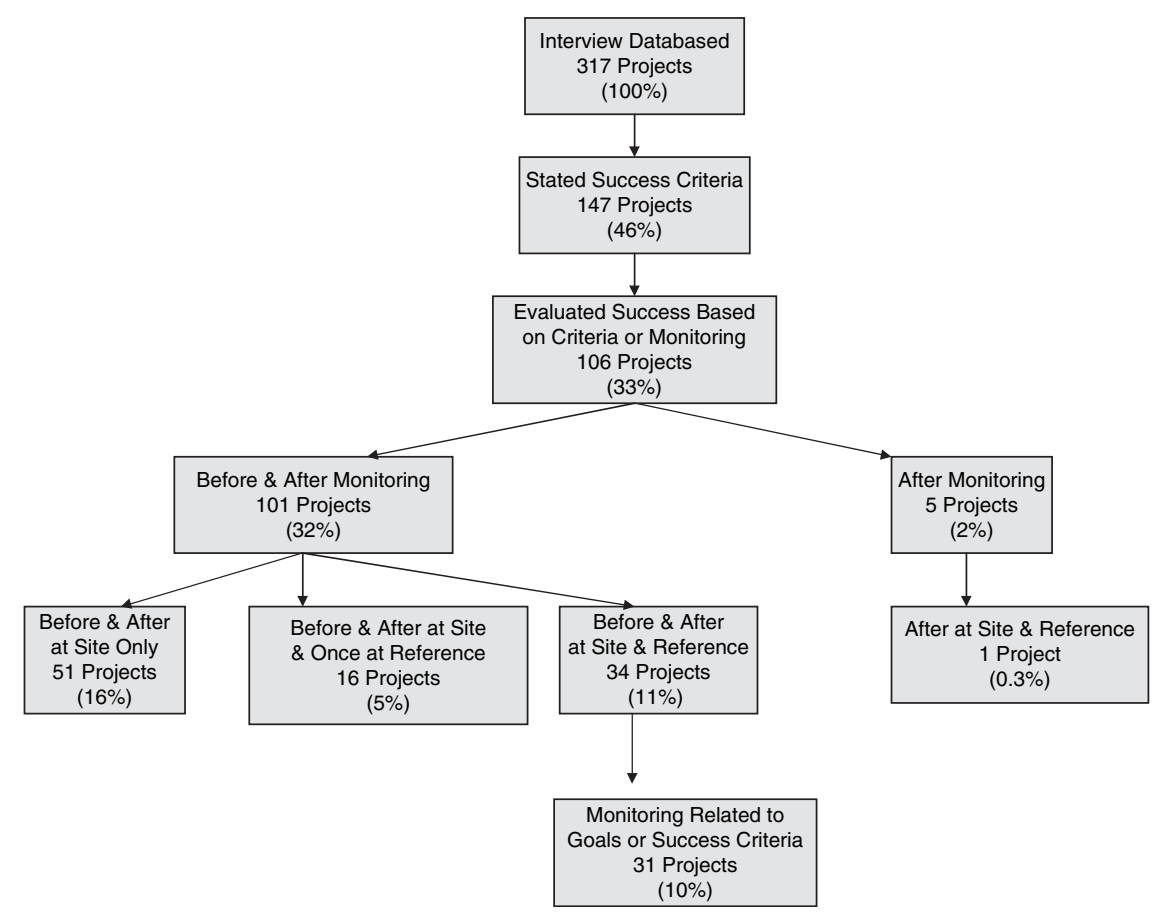

Figure 2. The idealized restoration process showing the proportion of projects within the NRRSS Interview Database that met increasing levels of rigor in their design and evaluation. 
Table 4. The distribution of monitoring effort over time at the restoration site and over time at a reference site.

\begin{tabular}{|c|c|c|}
\hline $\begin{array}{l}\text { Timing and Location of Monitoring } \\
\text { Relative to Implementation }\end{array}$ & $\begin{array}{l}\text { \# of } \\
\text { Projects }\end{array}$ & $\begin{array}{l}\text { \% Survey } \\
\text { Projects }\end{array}$ \\
\hline Before/after treatment/reference & 78 & 25 \\
\hline $\begin{array}{l}\text { Before/after treatment } \\
\text { before or after reference }\end{array}$ & 14 & 4 \\
\hline Before/after treatment only & 127 & 40 \\
\hline After treatment only & 1 & 0.3 \\
\hline Before treatment only & 22 & 7 \\
\hline
\end{tabular}

interviewed projects, a finding that conflicts with the results of our earlier synthesis effort. For the full dataset of approximately 37,000 U.S. river restoration projects, we found that only approximately $10 \%$ of written project records indicated any form of monitoring (Bernhardt et al. 2005). The true rate at which projects are monitored is certainly higher than $10 \%$ but almost certainly lower than $83 \%$. Two factors are likely responsible for this discrepancy. First, written project records and databases designed to track projects often fail to record monitoring information. Many databases lack an entry field for project monitoring so there was no "prompt" for this information. Second, as discussed earlier, the projects within our interview database are a skewed subsample, representing the more expensive and larger restoration efforts performed by long-term practitioners of restoration.

Despite these high monitoring rates, project contacts indicated that quantitative measurement data were used to evaluate project success in only $59 \%$ of our interviews. Project contacts told us that many of the projects ( $29 \%$ ) for which monitoring data were collected did not use those data to evaluate success. In fact, $47 \%$ of project contacts indicated that their assessment of project success was based primarily on site observations (nonquantitative assessment such as pre- vs. post-implementation site visits or photographic documentation) or positive public opinion.

\section{Common Elements of Restoration Success}

The ultimate goal of the NRRSS project, and the question our working group has been most frequently asked, is "what works?" in the context of river restoration. Although a definitive answer to this question requires many more years of experimentation and analysis, we can use the interview data to examine project effectiveness in several ways. First, we can ask, did projects that were deemed completely successful by project contacts have any features that were distinct from projects deemed only partially or not successful? Second, we can ask whether projects that followed the idealized process we outlined above (Fig. 2) had any unique attributes. Third, we can determine if projects that received high scores in our post hoc analysis of ecological successes (sensu Palmer et al. 2005 ) were in any way distinct from the overall pool.
A large number of analyses to address these three questions can be distilled to a few simple findings. With respect to the first question, we found that there were no detectable differences (e.g., in motivation, members of the restoration team, funding sources) between projects that interviewees deemed completely successful and those deemed only partially successful or not at all successful, except for the finding that projects deemed less than completely successful were more likely to have had both preand post-implementation project monitoring. This suggests that field evaluation of project outcomes is likely to temper conclusions about project effectiveness. With respect to the second question, the 31 projects that followed the idealized process (Fig. 2) were not distinct from the full dataset in terms of project costs, project size, the composition of project participants, the funding source, or the region in which the project was performed. Indeed, the only distinction that we can draw between these projects employing a "highly effective process" and the full dataset is that more than two-thirds of these projects had significant community involvement and had an advisory committee associated with the project (Table 5).

With respect to our post hoc evaluation of "ecological success" (sensu Palmer et al. 2005), the 23 projects that received the highest scores (top 10) in each of our three ecological success categories (Fig. 3) were not distinct from the full dataset in any way except for the extent of community involvement and the proportion of these projects that had an advisory committee. For the eight projects that both followed the "idealized process" and were among the highest scoring projects in our ecological success categories, six had an advisory committee and seven had significant community involvement. This compares to the full dataset where less than half of all projects had an advisory committee and only half had significant community involvement (Table 5). Project contacts for this best managed subset were no more likely to judge these projects completely successful than the ratio found for the full interview dataset.

\section{Conclusions}

River restoration is an increasingly common watershed management approach in the United States; yet, there is currently little information for evaluating the effectiveness of these efforts in improving the ecological conditions of restored streams. The goal of river restoration scientists, practitioners, and water resources managers should be to increase the ecological and cost-effectiveness of restoration strategies, enabling us to improve the environmental conditions for the highest possible number of degraded stream miles in the United States (Palmer \& Allan 2005). Common restoration practices are in need of rigorous scientific evaluation to determine whether these efforts lead to the desired ecological outcomes (Hobbs 2005). In addition, management agencies need to reevaluate their guidelines for funding or permitting restoration projects in 
Table 5. Comparison of projects that met NRRSS criteria for success versus the full interview database.

\begin{tabular}{|c|c|c|c|c|}
\hline & $\begin{array}{c}\text { High-Ranking Projects } \\
\text { in Ecological } \\
\text { Success Categories }\end{array}$ & $\begin{array}{l}\text { Projects Following } \\
\text { Idealized } \\
\text { Restoration Process }\end{array}$ & $\begin{array}{c}\text { Projects that } \\
\text { Followed Idealized } \\
\text { Process and Received } \\
\text { a Top } 10 \text { Score } \\
\text { in at least } \\
\text { One Ecological } \\
\text { Success Category }\end{array}$ & $\begin{array}{c}\text { Interview } \\
\text { Database-All Projects }\end{array}$ \\
\hline Number of projects & 23 & 31 & 8 & 317 \\
\hline Median length (m) & 907 & 1,510 & 1,066 & 914 \\
\hline Mean \# of funders & 4.4 & 4.4 & 3.9 & 3.6 \\
\hline Mean \# of partners/agencies/entities & 8.8 & 8.4 & 8.6 & 7.1 \\
\hline$\%$ with advisory committee & 70 & 60 & 80 & 40 \\
\hline$\%$ public involvement* & 64 & 68 & 79 & 49 \\
\hline
\end{tabular}

* For this metric, we averaged participation across the three project phases (design, implementation, and evaluation).

order to foster a more informed and accountable process for all restoration efforts. Many of the restoration practitioners that we spoke with are frustrated by the lack of funding for and emphasis on project monitoring. They are eager to improve project monitoring and information sharing.

Results from our interviews show that for many projects, there is less than perfect integration between project phases. Too often, goals are not clearly linked to objective success criteria, and data collected to evaluate projects are either not directly relevant to project goals or not utilized in evaluating project effectiveness. The process by which the typical restoration project is conducted is thus not as effective as it could be. Ecological benefits may accrue to projects where goal setting, implementation, and evaluation are disconnected from one another; but when clearly stated intentions guide the process, the likelihood of achieving the end result, or at least of learning why this result was not achieved, is much higher.

There are many reasons why projects are not monitored, or, if they are monitored, why that information is not used or shared. For most project contacts, monitoring was not done or results were not disseminated due to a lack of resources (time and money) rather than any unwillingness to evaluate projects. Clearly, the entities that fund and permit restoration need to provide additional resources as well as new regulations to make project evaluation and data sharing a funded mandate rather than an optional expense. However, given the thousands of restoration projects implemented each year, it is perhaps unreasonable to suggest that every project be evaluated to determine the ecological outcome. Indeed, we suggest that the "scientific standard" (Fig. 2) for evaluating restoration project outcomes may be inappropriate for the individual project. Rather, we argue that a rigorous statistical sampling of the population of restoration projects would provide more widely useful information to guide future efforts (Palmer \& Allan 2005). Currently, there are many small-scale efforts to measure restoration impacts but they vary greatly in their goals, are uncoordinated with one another and measure different factors, at different temporal and spatial scales and with different techniques (Roni et al. 2002). We argue that the health of our nation's rivers would be better served by pooling these resources and performing rigorous and coordinated monitoring on a much smaller number of carefully selected projects. This recommendation regarding outcome monitoring does not mean that more traditional monitoring to determine whether project implementation was carried out as designed or whether project features require maintenance (implementation monitoring) should not be performed. Indeed, we urge implementation monitoring for every river restoration project. At present, practitioners make little distinction between permit monitoring, implementation monitoring, and outcome monitoring. Requirements for each type need to be made clear and distinct by funding and management entities.

Our interviews demonstrate that the scientific method is playing only a minimal role at present in the practice of river restoration, with only a very few projects following an idealized process for evaluating project effectiveness. It is also clear that scientific research-published in the traditional venues-is unlikely to make its way quickly into restoration practice (Shields et al. 2003). Indeed, only one of more than 300 interviewees mentioned that a scientific paper significantly informed the design and implementation of a project. This lack of information transfer is due in no small part to the lack of scientific studies of restoration effectiveness to date (Roni et al. 2006); but our interviews make it abundantly clear that merely conducting and publishing more scientific studies will not lead to quick improvements in restoration practice. Restoration science must provide timely and relevant research to the federal and state agencies that are responsible for funding and implementing the vast majority of river restoration projects. Agency and academic scientists must engage 

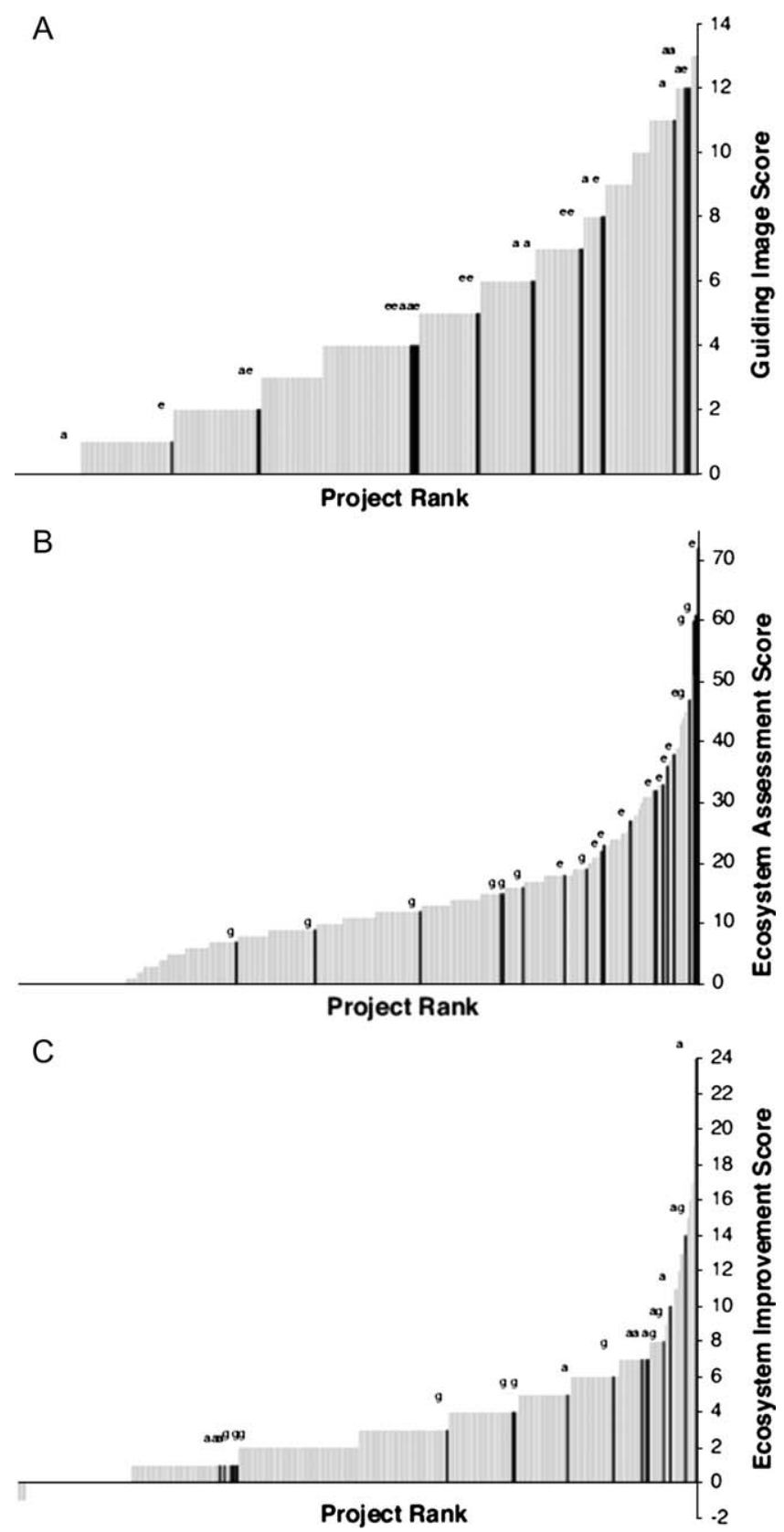

directly with managers to develop rigorous standards for the process by which restoration is done and in generating new scientifically sound strategies for meeting restoration objectives (Falk et al. 2006).

An interesting outcome of our post hoc evaluation of effective restoration projects was our discovery that the extent of community involvement was much higher at all stages of the process for this subset of projects than for the full dataset. Although our interviews did not allow us to understand how community involvement impacted the process, we hypothesize that community involvement increases project accountability. Projects that require or solicit stakeholder involvement will likely require clear descriptions of project goals, actions, and achievements. Projects that are vetted by a larger number of participants may benefit, regardless of the specific form of stakeholder involvement. Involving advisory boards or holding public meetings about restoration projects may provide a useful checkpoint, forcing project designers and funders to clearly define their goals, actions, and evaluation strategy. Several interviewees mentioned that these types of interactions can stall or impede restoration projects, and clearly, public involvement and oversight are not a cureall. However, management agencies are likely to benefit from strategically soliciting stakeholder and expert opinions.

With $45 \%$ of our nation's rivers classified as endangered or impaired (U.S. EPA 2000), we cannot be content with only protecting the remaining "supporting" rivers and streams. Active management is necessary to reverse the declines in water quality and the loss of critical freshwater habitat. River restoration will continue to be an important part of the management toolbox. If individual restoration projects prove effective at reaching their ecological goals, then it is likely that a higher proportion of management dollars will be spent using similar strategies. When restoration projects prove ineffective, it is as important that we gain information to understand what does and does not work. We urge practitioners, managers, and policymakers to view individual restoration projects as experiments and opportunities to learn and improve our understanding of river ecosystems. Then, we can expect the entire enterprise of river restoration in the United States to succeed in preventing and reversing river degradation.

Figure 3. The distribution of "effectiveness" scores along three axes of ecological success for restoration projects. Shown in black on each frequency histogram are projects that were ranked in the top 10 in one of the other two categories. In (A) GUIDING IMAGE: projects were ranked based on whether explicit success criteria were stated and whether project goals linked with watershed and river basin planning. All three of the highest scoring projects in this category were conducted as part of a watershed plan, were coordinated with other projects in the watershed, and stated measurable success criteria. In (B) ECOSYSTEM ASSESSMENT: projects were ranked based on the extent, duration, frequency, and statistical rigor with which project monitoring was done. In (C) ECOSYSTEM IMPROVEMENT: projects were ranked based on whether any the project contact told us that measurable improvements had occurred in the restored system. The highest scoring project for both assessment and improvement was an acid mine drainage restoration project that conducted extensive monitoring (12 variables, combination of chemical, physical, and biological measurements) for several years prior to and following project implementation at both the project site and a nearby reference stream. Improvement was documented in 11 of the 12 measured variables. Only one project achieved a top 10 score for all three categories, this was a restoration project initiated by a state governor with the purpose of improving water quality for which 11 separate chemical and biological variables were monitored for several years prior to and after the restoration project. 


\section{Implications for Practice}

- For the majority of river restoration projects, project phases (1. goal setting; 2. design; 3. implementation; and 4. evaluation) are disconnected from one another, reducing the likelihood of achieving the intended result.

- Although many projects include some form of monitoring, the data collected often are not used to evaluate projects because either (1) data collected are not directly relevant to project goals or (2) data are insufficient or the monitoring design is inadequate to perform a rigorous evaluation.

- Academic and agency scientists must engage directly with restoration practitioners to transfer existing knowledge and to generate new information that can help guide the restoration enterprise toward the highest possible ecological benefits at the lowest possible costs in order to restore the maximum number of stream miles.

\section{Acknowledgments}

We thank the 317 individuals who took time out of their busy schedules to talk with us about their restoration projects, and the hundreds of individuals who helped us track down these willing participants. We thank Ben Best, Duke University, who designed and implemented our survey database under significant time pressures and with excellent results. Remi Treuer has proven invaluable in synthesizing the interview information. Computer support staff at Duke facilitated data sharing, protection, and synthesis; we give special thanks to Hunter Matthews for implementing our project WIKI. Meetings of the NRRSS working group have been supported by the National Science Foundation's National Center for Ecological Analysis and Synthesis (NCEAS). The national effort received support from the U.S. National Science Foundation, U.S. Geological Survey (USGS), the David and Lucille Packard Foundation, Altria, and the U.S. EPA. Individual regional teams received support from the C. S. Mott Foundation, the CRC for Freshwater Ecology, the McKnight Foundation, California Bay Delta Authority, the U.S. Bureau of Reclamation, University of Maryland, and the Maryland Department of Natural Resources. We thank M. Bowman, K. Ransel, and A. Fahlund at American Rivers for their contributions to this project. USGS National Biological Information Infrastructure (NBII) provided invaluable personnel support; we particularly thank B. Powell, G. Cotter, and M. Frame. We thank all data providers, particularly Staff of the Northwest Fisheries Science Center of the National Oceanic and Atmospheric Administration, including M. Ehrhart, S. D. Kunkoski, M. Wiley, and P. Steen; also R. Carlson and K. Ward who provided us with previously synthesized regional databases. Views expressed here do not represent the views of any supporting organization or data provider.

\section{LITERATURE CITED}

Baruch, Y. 1999. Response rate in academic studies-a comparative analysis. Human Relations 52:421-438.

Bash, J. S., and C. M. Ryan. 2002. Stream restoration and enhancement projects: is anyone monitoring? Environmental Management 29:877-885.

Bernhardt, E. S., M. A. Palmer, J. D. Allan, G. Alexander, K. Barnas, S. Brooks, et al. 2005. Synthesizing US river restoration efforts. Science 308:636-637.

Dahm, C. N., K. W. Cummins, H. M. Valett, and R. L. Coleman. 1995. An ecosystem view of the restoration of the Kissimmee River. Restoration Ecology 3:225-238.

Downs, P. W., and G. M. Kondolf. 2002. Post-project appraisals in adaptive management of river channel restoration. Environmental Management 29:477-496.

Falk, D. A., J. B. Zedler, and M. A. Palmer, editors. 2006. Foundations of restoration ecology. Island Press, Washington, D.C.

Frary, R. B. 1985. Multiple-choice versus free-response-a simulation study. Journal of Educational Measurement 22:21-31.

Heppner, P. P., J. D. M. Kivlighan, and B. E. Wampold. 1992. Research design in counseling. Brooks Cole, Pacific Grove, California.

Hobbs, R. J. 2005. The future of restoration ecology: challenges and opportunities. Restoration Ecology 13:239-241.

Kondolf, G. M. 1995. 5 elements for effective evaluation of stream restoration. Restoration Ecology 3:133-136.

Kondolf, G. M., and E. R. Micheli. 1995. Evaluating stream restoration projects. Environmental Management 19:1-15.

Leong, F. T. L., and J. T. Austin, editors. 1996. The psychology research handbook. Sage, Thousand Oaks, California.

Moerke, A. H., and G. A. Lamberti. 2004. Restoring stream ecosystems: lessons from a midwestern state. Restoration Ecology 12:327-334.

NRC (National Research Council). 1992. Restoration of aquatic ecosystems: science, technology, and public policy. National Academies Press, Washington, D.C.

Palmer, M. A., and J. D. Allan. 2005. Restoring rivers. Issues in Science and Technology 22:40-48.

Palmer, M. A., E. S. Bernhardt, J. D. Allan, P. S. Lake, G. Alexander, S. Brooks, et al. 2005. Standards for ecologically successful river restoration. Journal of Applied Ecology 42:208-217.

Pedroli, B., G. de Blust, K. van Looy, and S. van Rooij. 2001. Setting targets in strategies for river restoration. Landscape Ecology 17:5-18.

Postel, S., and B. Richter. 2003. Rivers for life: managing waters for people and nature. Island Press.

Roni, P., T. J. Beechie, R. E. Bilby, F. E. Leonetti, M. M. Pollock, and G. R. Pess. 2002. A review of stream restoration techniques and a hierarchical strategy for prioritizing restoration in Pacific northwest watersheds. North American Journal of Fisheries Management 22:1-20.

Roni, P., K. Hanson, T. Beechie, G. Pess, M. Pollock, and D. M. Bartley. 2006. Habitat rehabilitation for inland fisheries. Global review of effectiveness and guidance for rehabilitation of freshwater ecosystems. No. 484, FAO, Rome, Italy.

Ruiz-Jaen, M. C., and T. Mitchell Aide. 2005. Restoration success: how is it being measured? Restoration Ecology 13:569-577.

Shields, F. D., C. M. Cooper, S. S. Knight, and M. T. Moore. 2003. Stream corridor restoration research: a long and winding road. Ecological Engineering 20:441-454.

Sudduth, E. B., J. L. Meyer, E. S. Bernhardt. 2007. Stream restoration practices in the Southeastern United States. Restoration Ecology 15:572-583.

Wohl, E., P. L. Angermeier, E. Bledsoe, G. M. Kondolf, L. MacDonnell, D. M. Merritt, M. A. Palmer, N. L. Poff, and D. Tarboton. 2005. River restoration. Water Resources Research 41:W10301.

U.S. EPA (Environmental Protection Agency). 2000. National Water Quality Inventory, Environmental Protection Agency Office of Water. EPA-841-F-02-003, http://www.epa.gov/305b.

Yu, J., and H. Cooper. 1983. A quantitative review of research design effects on response rates to questionnaires. Journal of Marketing Research 20:36-44. 